\title{
Information Seeking Behaviour of Undergraduates about Higher Educational Opportunities in Sri Lanka: Online or Offline?
}

\author{
K A Vidyanjalie Abeygunawardena \\ Faculty of Education, University of Colombo, Sri Lanka
}

\begin{abstract}
International Degree Programmes emerged as a domestic option in Sri Lanka affiliated to private higher educational institutes (PHEIs). As it is highly competitive, PHEIs implement their Bachelor's degree programmes differently to attract prospective student where social media platforms use to disseminate more informed information. However, this study attempts to discuss how undergraduates seek information at an early stage of their decision-making process when selecting their preferred Bachelor's degree. The questionnaire with 59 predefined variables administered by 420 first-year undergraduates from randomly selected seven PHEIs. Educating stakeholders for the digital world is significant since the penetration of social media still plays a secondary role in seeking information.
\end{abstract}

Keywords: Bachelor's Degree, Gender Differences, Information sources, Prospective Students, Social Media

\section{Introduction}

Internationalization is a term used to discuss the international dimension of higher education and, it is more widely in post-secondary education (Knight, 2007). As stated by Knight (2012), the demand for international education is expected to be 7.2 million in 2025 and, foreign universities may have the challenge to provide their Bachelor's degrees (BD) for international students parallel to domestic students. As a result of internalization in education, the top-ranked foreign universities leads to offer their International degree programmes (IDPs) through cross border education for international students to overcome the challenges in student mobility where academic programmes move across national jurisdictional borders instead of students (Knight, 2007). Consequently, IDPs emerged in Sri Lanka affiliated with private higher educational institutes (PHEIs) as a domestic option to fulfill the university level education due to the intense competition in National university admission (Abeygunawardena, 2018a). In the present context, the higher education industry is increasingly competitive and facing more complex challenges in attracting students for enrolments (Abeygunawardena, 2018a). Indeed, selecting a BD has become strategically complicated in Sri Lanka due to optionality and flexibility of the BDs offered in IDPs (Abeygunawardena, 2018a). Apart from that, the students' decision influenced by several demographic, economic, social and psychological factors where the decision-making process is complex and multifactorial (Kusumawati, Yanamandram, \& Perera, 2010). Thereby, university choice is a high-risk decision for prospective students which require substantial effort to evaluate a range of choice factors. Alternatively, the choice behaviour of prospective students when selecting their preferred BD may vary due to the available information (Abeygunawardena, 2018c). Therefore, it is imperative to identify the validity of information shared through various online and offline sources to make the optimal decision. The difference between 'correct' and 'wrong' choices of prospective students can be difficult to comprehend at an early stage of the decision-making process (Yorke, 1999). Indeed, sub-optimal choices of students would impact negatively on their motivation and academic success, which may lead to student dissatisfaction (Ozga \& Sukhandan, 1998). Therefore, it is essential to investigate the role of PHEIs in marketing their BDs offered in IDPs along with their featured characteristics as the knowledge transmitter between the prospective student and the foreign university. As a result, educational marketers are increasingly utilizing social media as a strategic communication tool to 
support student recruitment (Hayes, Ruschman \& Walker, 2009; Fagerstrom \& Ghinea, 2013). However, the importance of social media as platforms of social interaction, communication and marketing is growing in this digital age (Rutter, Roper \& Lettice, 2016). Thereby, consumers are increasingly seeking information from social media rather than traditional media channels (Mangold \& Faulds, 2009). Indeed a global survey on international higher education by Hobsons (2017) illustrates that more than $80 \%$ of prospective students use social media to research their BD choice which remarks the increasing importance of social media as one of the most popular information channels for prospective students (Rowe, 2014; Galan, Lawley \& Clements, 2015). Social media comprise of a wide range of online platforms such as discussion boards, social networking sites, video and photo sharing sites and, question and answer sites, which feature different functions and activities to deliver information (Mangold \& Faulds, 2009). Alternatively, parents and family members are significant in BD selection because prospective student may receive different viewpoints from them for a better choice due to their experience and market demand (Soutar \& Turner, 2002). Indeed, prospective rated Word-Of-Mouth (WOM) as a reliable source of information during their decision-making process since it shares the real experiences and viewpoints of graduates about their BD choice (Patti \& Chen, 2009).

In several developed countries use social media as one of the most powerful marketing tools to share WOM activities to reinforce decision making (Kimmel \& Kitchen, 2013; Rowe, 2014). An increasing number of PHEIs in Sri Lanka is moving forward to integrate social media applications into their BD marketing campaigns (Abeygunawardena, 2018c). Consequently, they make various types of online and offline marketing tools to enhance the awareness of their BDs and characteristics of PHEIs to increase their student intake (Abeygunawardena, 2018c). However, it is essential to investigate the prospective students' preferences about information sources and the effectiveness of social media as a marketing tool to promote the BDs. Therefore, this study analyses the information-seeking behaviour of prospective Sri Lankan students in their preferred BD choice across different types of BDs in IDPs.

\section{Objectives}

The research addresses two key questions:

1. To identify the importance of information sources in today's digital age in selecting a BD from IDPs?

2. To identify any gender impact on student behaviour in accessing those information sources?

\section{Literature Review}

The higher education is a credence based service with the characteristics of intangibility, perishability, simultaneity and variability (Brown, Varley \& Pal, 2009; Simões, \& Soares, 2010). Therefore, most of its characteristics are difficult to evaluate even after purchase and consumption (Patti \& Chen, 2009; Walsh, et al., 2015). The choice of a BD is usually a one-off decision which results in an extended consumption of three to four years with a long-term impact on the career prospects of the student (Walsh, et al., 2015). Therefore, the selection of a $\mathrm{BD}$ is a high-risk decision in which perceived risk occurs due to financial, psychological, functional and social impacts (Simões \& Soares, 2010). Additionally, the students' choice in selecting a PHEI and a $\mathrm{BD}$ is subjective and, it varies within the decision-making process which starts from the time when they recognize the need of higher education and finishes with the enrollment ((Maringe, 2006; Vrontis, Thrassou \& Melanthiou, 2007; Stephenson, Heckert \& Yerger, 2016). As a result, the consumer involvement in decision making process expands due to this perceived risk and the uniqueness of the BDs available. Indeed, prepurchase stage of the decision-making process comprises with recognition of the need of higher education, information search and evaluation of alternatives (Moogan and Baron, 2003; Brown, Varley \& Pal, 2009). However, when prospects identify their need to gain a higher education degree, they search for relevant information and evaluate potential choices sequentially within the pre-purchase stage of the decision-making process (Moogan \& Baron, 2003). Besides prospects behaves as rational consumers when selecting the PHEI 
and the BD to enrol where they focus on a list of PHEIs and BD options prepared according to their choice factors (Tavares \& Cardoso, 2013). Consequently, several models have developed since 1980 to explain the multistage and multifactorial decision-making process due to risk attain in selecting a BD from several other alternatives (Moogan and Baron 2003; Cubillo, Sánchez, \& Cerviño, 2006). The Chapman's combined model (1981) focused on the impact of student characteristics, sources of information, institutional characteristics and marketing tools on students' choice in selecting a BD (Migin, Falahat \& Khatibi, 2015). Indeed, Hanson and Litten's (1989) model comprised of 5 different stages, including college aspirations, search, information gathering, sending applications and enrolling (Maniu \& Maniu, 2014). Subsequently, the model developed by Maniu \& Maniu (2014) also explains the impact of curriculum, career prospects, costs, infrastructure, location, social life and university reputation in addition to the reference groups on students' choice. Additionally, the model of Vrontis, Thrassou and Melanthiou (2007), remarks the importance of students' and university characteristics, influencers and environments on students' decision in selecting a BD. Alternatively, the marketing mix has instigated additionally to the model developed by Alonderiene \& Klimavičiene (2013) compared to others. However, most of these latest models developed towards consumer behaviour theories in which post-purchase behaviour introduces to comprehend the effectiveness of the students' choice. Subsequently, the 5 stage decision-making model developed by Abeygunawardena (2018b) for Sri Lankan prospective students follows consumer behaviour theories which include 'consumption' as the last stage. As this is another stage in the decision-making process, students get an opportunity to change the BD if they realize the preferred BD deviates from their expected educational objectives. Therefore, students get an opportunity to revisit 'information search' (2nd stage) or 'evaluation of alternatives' (3rd stage) to refine their initial decision.

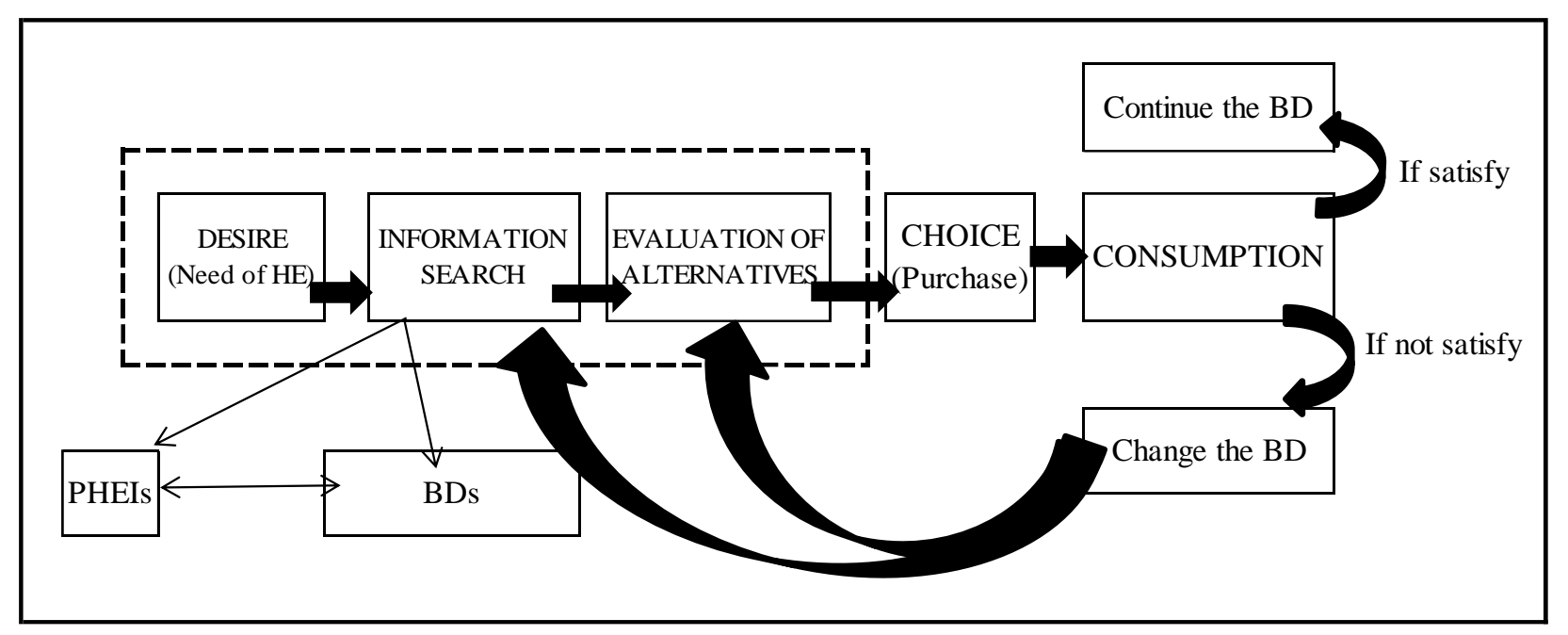

Figure 1: Decision making model for selecting a BD from IDP in Sri Lanka

(Source: Abeygunawardena K A V, 2018b)

\section{Heuristic decision making of prospective students}

According to Abeygunawardena (2018b), the process of decision making is affected by endogenous factors (student's characteristics) and exogenous factors (environmental variables). Subsequently, people make conscious efforts to make decision rationally using the assumptions and accepting the limits of available information. Indeed bounded rationality explains the limitations on the decision-making process due to cognitive abilities and time constraints towards in optimizing the decision (Venkatesh, Morris \& Ackerman, 2000). However, people tend to believe information as evidence when making decisions and decisions are faster when high-quality evidence is available (Abeygunawardena, 2019). Alternatively, low-quality evidence delay the decision since people may search for additional information. Therefore, people tend to make a heuristic 
decision which allows in making decisions quickly and with ease to prioritize some information over the other. Heuristics are mental shortcuts used by people to reduce the complexity and cognitive burden associated with decision-making (Abeygunawardena, 2019). Therefore, prospective students' decision may depend on heuristics since they tend to follow what others do even though the information is readily available to compare the alternatives to make their own decisions.

\section{Influential factors on students' choice in selecting a BD and the university}

Due to the competition in private higher education sector (Dao \& Thorpe, 2015), university marketers need to identify the choice factors and information sources impact on students to develop marketing strategies for student recruitment (Simões, \& Soares, 2010). A large number of studies have conducted globally to investigate choice factors during the last two decades (Hemsley-brown \& Oplatka, 2015). Indeed few studies identified choice factors as the attributes of the service or the characteristics of PHEI (Moogan \& Baron, 2003; Veloutsou, Lewis \& Paton, 2004; Bonnema and Van der Waldt, 2008; Obermeit, 2012). Thereby, according to those studies, prospective students seek information about the reputation of the institution, tuition fees, course availability, content of the specific course, and distance from home when selecting a university to pursue a BD. Alternatively, a few other studies defined choice factors as a combination of institutional and students' characteristics and sources of information (Maringe, 2006; Dao \& Thorpe, 2015; Hemsley-Brown \& Oplatka, 2015). As indicated by Soutar and Turner (2002), the top four determinants to select the university in Western Australia were 'course suitability', 'academic reputation of the university', 'job prospects' and 'teaching quality'. Therefore, the list of choice factors in selecting a BD and the PHEI diversified across empirical studies.

\section{Importance of information sources on Students' choice of a BD and the university}

PHEIs need to identify various sources of information highlighted by prospective students in previous studies to strengthen the information through those sources to attract students (Veloutsou, Lewis and Paton, 2004). As stated by Bonnema \& Van der Waldt (2008), Simões, \& Soares (2010) and Obermeit (2012), prospective students seek information through a wide range of sources during their decision-making process. Thereby prospective students prioritize different sources based on the preferred information since information might be different among several sources (Bonnema \& Van der Waldt, 2008). In the present private higher education market, information through parents and friends rated as most influential sources of information (HemsleyBrown \& Oplatka, 2015) whereas Word-Of-Mouth rated as the most effective promotional tool (Mazzarol and Soutar, 2002; Kimmel \& Kitchen, 2013). The work of Briggs \& Wilson (2007) about Scottish undergraduates' choice explained more about information delivered through WOM sources and, expressed the importance of establishing future research on WOM processes, especially in higher education. Extensively, due to the emergence of digital communication channels at present conditions, social media and the internet plays an important role when delivering information to prospective (Obermeit, 2012). As the impact of social media on BD selection (Galan, Lawley \& Clements, 2015), many PHEIs initiated to use social networking platforms as a marketing tool due to the growing popularity of it over the traditional marketing. Thereby, information on websites acts as self-representations of the PHEIs, not merely as one of the information sources (Misley \& Vamos, 2017). However, communication in the present digital age is fast and dynamic since the modern technological devices such as smartphones and, tablets enabling continuous 'plug-in' virtually everywhere (Hayes, Ruschman \& Walker, 2009). Thereby prospective students, parents and other interested parties tend to use social networking sites to get information about PHEIs and BDs instantly irrespective of their location. Therefore, PHEI should assess this shift in behaviour to implement successful communication with their prospective potential students. However, few research studies conducted in Bosnia and Herzegovina remarked that social networking sites and Facebook profile are the most common information sources among prospective student, which was second only to YouTube channels of PHEIs (Hayes, Ruschman \& Walker, 2009). Additionally, posts on Twitter, LinkedIn, Instagram and Google + are using to share news about academic events and advancements to remark them over other competitors (Rowe, 2014). However, due to the risk 
involve with the individual decision in higher education, people may rely more on information through Wordof-mouth sources such as friends, parents', teachers and career advisors (Moogan \& Baron, 2003; Wilkins \& Huisman, 2015; Voyer \& Ranaweera, 2015). Thereby, it is essential to conduct segmentation analysis to identify the importance of choice factors together with information sources in BD selection since their ratings may vary across student segments (Wong et al., 2018). Even though, social media involvement in marketing campaigns of PHEIs discussed (Fagerstrom \& Ghinea, 2013; Rutter, Roper \& Lettice, 2016), the studies about the effectiveness of social media for prospective students as information sources are limited. However, it is imperative to study the importance of information sources compared to other influential factors during the decision making process since students' choice in selecting a BD from IDP are minimal in the Sri Lankan context. Hence, the present study attempts to identify the students' behaviour in seeking information about PHEIs and BDs during the decision-making process and to investigate what sources of information prioritise in their preferred choice.

\section{Materials and methods}

The survey study was designed to capture students' perception of factors that had influenced their decision in selecting a BD in IDPs, immediately following the decision-making process. Factors identified as Influential on students choice in selecting a BD by previous other studies have identified through the literature. Additionally, the official documents of PHEIs referred to get awareness about the BDs and the characteristics of PHEIs. Undergraduates of BSc, BEng, BA.BBA degrees have selected as respondents for the present study since industry demand direct for STEM and management related disciplines. All PHEIs who offer BDs through IDPs categorized into BSc, BEng and BA/BBA using stratified random sampling and, 3 PHEIs have selected from each stratum using simple random sampling. As several PHEIs conducts more than one type of BDs, some of the PHEIs have selected more than once for the sample. As a result, 7 PHEIs selected randomly to collect 420 first-year students for the survey study. The target population of the study is 'all undergraduates enrolled for a BD in an IDP in PHEIs". The questionnaire prepared mainly to employ the students' rating for the 59 predefined variables with a scale of 1 (strongly agreed) to 5 (strongly disagreed) which perceived important in their choice decision. A pilot study conducted twice to investigate the adequacy of the questionnaire using first-year $(n=45)$ and second-year $(\mathrm{n}=45)$ undergraduates of IDPs. Indeed, senior academics revised the prepared questionnaire based on the specific objectives of the study. Additionally, reliability tests have conducted using SPSS to check the appropriateness of the data set for factor analysis.

\section{Results}

Firstly, the descriptive analysis conducted for the entire data set to get an idea about the sampling units based on the scores of the demographic variables in the questionnaire before the factor analysis. In the sample, $76.9 \%$ of the respondents are Sinhalese and, $67.4 \%$ are from the Western province. Indeed, $49.5 \%$ of the respondents are from National schools and, only $18.1 \%$ are from international schools. Furthermore, around $75 \%$ of students and $68 \%$ of students in the data set obtained, "A" grades for English and Mathematics respectively. Parents of most of the respondents are with a higher level of educational qualification in which more than $50 \%$ of the parents have a BD and, $63 \%$ of the parents have a monthly earning less than Rs.200,000/=. However, around $81.8 \%$ of the first-year undergraduates in the sample have passed their ordinary level examination in the national curriculum. In that, only $76.9 \%$ continued their advanced level examination in the National curriculum and $15.5 \%$ of those qualified for National university admission. Of those, more than $40 \%$ of them enrolled for IDPs since that have not selected for their first preferred choice. According to the respondents' statistics, $6.7 \%$ have changed their first choice of the BD after a few months and, only $77 \%$ have enrolled for the first preferred PHEI to pursue a BD.

Secondly, data were analysed using SPSS and, Factor analysis used as a data reduction method to identify the most influential factors on students' choice in selecting a BD. Indeed, the reliability test was conducted by 
investigating Cronbach's alpha value before the factor analysis. However, the Cronbach's alpha value of 59 variables in the questionnaire was found to be 0.939 , which confirmed the data set is reliable for factor analysis. As the Cronbach's alpha value is higher than 0.7, all items in the questionnaire are reliable and internally consistent for data collection (Saunders, Lewis \& Thornhill, 2012). Furthermore, Kaiser-Meyer-Olkin's (KMO) overall measure of the sample was 0.886 , which is considered as acceptable since the score is higher than 0.6 (Tabachnick \& Fidell, 2013). Moreover, Bartlett's test of Sphericity was significant (Chi-Square value is approximately 14545.762 with 0.000 significant value). Both KMO and Bartlett's test scores confirmed that the data set is appropriate for factor analysis. The principal component analysis (PCA) was the approach used in factor analysis which explains the variation by each component. Indeed, the Scree plot used to identify as to how many factors need to extract which found out by PCA. The point of interest is where the scree plot starts to flatten. In the entire sample, $56.46 \%$ of the total variation explained by the 8 components extracted by the PCA. But the scree plot identified that the contribution of the first 7 th components is significant. The Varimax rotation used to maximize the number of variables with higher factor loading on to each component separately (Field, 2005). Later, the extracted components labeled meaningfully based on the individual variables classified into each.

\section{Discussion}

The importance placed for information sources (websites, paper advertisements, prospectus and parents) and peer impact were not rated as influential by undergraduates compared to other choice factors in the entire sample. Indeed 'sources of information' and 'peers' rated as 6th and 7th influential factors which explained 3.6\% and $2.868 \%$ of the total variation. Thereby it is imperative to study how students seek information about other choice factors before their decision. As indicated by descriptive analysis for the entire group, males and females have differently rated the sources of information and other choice factors. Therefore the factor analysis conducted again for male and female groups separately to identify how they rated influential factors during the BD choice and results is displayed in table 1.

Table 1: importance of influential factors based on the gender of the undergraduate

\begin{tabular}{|l|c|c|l|c|c|}
\hline \multicolumn{2}{|c|}{ Female students } & \multicolumn{3}{c|}{ Male students } \\
\hline Factor (Labeled) & $\begin{array}{c}\text { \% of } \\
\text { variation }\end{array}$ & $\begin{array}{c}\text { \# of } \\
\text { variables } \\
\text { loaded }\end{array}$ & \multicolumn{1}{|c|}{ Factor (Labeled) } & $\begin{array}{c}\text { \% of } \\
\text { variation }\end{array}$ & $\begin{array}{c}\# \text { of } \\
\text { variables } \\
\text { loaded }\end{array}$ \\
\hline Infrastructure facilities & 23.485 & 9 & Infrastructure facilities & 25.88 & 9 \\
\hline Financial support & 10.203 & 4 & Cost \& Financial support & 10.015 & 7 \\
\hline Reputation of the university & 5.913 & 5 & University characteristics & 5.543 & 6 \\
\hline Programme evaluation & 5.499 & 6 & Marketing strategy & 5.283 & 5 \\
\hline Marketing strategy & 4.254 & 4 & Reputation of the university & 3.858 & 4 \\
\hline University characteristics & 3.745 & 4 & Programme evaluation & 3.828 & 5 \\
\hline First Impression & 3.125 & 4 & Messenger & 2.909 & 4 \\
\hline$\ldots \ldots .$. & $\ldots \ldots \ldots .$. & $\ldots \ldots .$. & Peer & 2.739 & 2 \\
\hline Total & $\mathbf{5 6 . 2 2 4}$ & $\mathbf{3 6}$ & Total & $\mathbf{6 0 . 0 5 5}$ & $\mathbf{4 2}$ \\
\hline
\end{tabular}

Remarkably, the 'sources of information' and 'peer' are influential only for male group and not for the female group. Alternatively, it is evident to confirm that the relevance placed by the female group for the Information through social media, prospectus, paper advertisements, peer and other references groups were not significant to 
identify by the factor analysis. Indeed the female group may not rely upon the information published through online and offline modes about the BDs and PHEIs. But the importance remarked by the male group for 'sources of information' and 'peer' is very low compared to all other influential factors determined by the factor analysis. Furthermore, the male group rated offline sources such as website, paper advertisement and prospectus influenced them for the BD selection and not online sources like social networking sites. But several PHEIs maintain their social networking sites very attractively in today's digital age to facilitate easy access through their mobile phones and other accessories at any time than the offline modes of communication. The male group rated 'peer' as an influential factor even it explains around $2.5 \%$ of the total variation in which they consider peer as a mentor to get advice for the optimal choice. That makes a debate about why female students have not rated any online or offline tools for information gathering.

As rated by the female group, $35.8 \%$ and $30.7 \%$ have agreed that 'websites' and 'paper advertisements' are influential for their BD choice respectively with different mean values (websites $=3.199 \&$ paper advertisement= 2.8). Even though female students have highlighted that parents and prospectus are influential for their BD choice with mean values (3.16 and 3.43), they have not extracted as influential by factor analysis. Alternatively, more than $70 \%$ of female students have agreed for the two statements about peer influence with high mean values of 4.04, and 3.92 respectively. However, 'peer' have extracted as an influential factor by the factor analysis, but it has not determined by the scree plot. As indicated by the female students, the open discussion with resources persons of PHEIs at educational exhibitions, Open days, school competitions and educational conferences have created a positive impression on their BD choice compared to the information available in online and offline sources. However, all these events grouped under 'first impression' which is the 7th influential factor for female students according to the PCA and the scree plot. However, those were rated as influential by more than $75 \%$ of female students. Further analysis was conducted using different grouping variables to identify the significant differences between male and female group about their information seeking modes when selecting a BD.

\section{Conclusions and suggestions}

The present study depicted that the students' behaviour in selecting a BD concerning social media is less important for both male and female groups. However, information from websites, paper advertisements, prospectus and parents are influential only for the male group while female group preferred information promotes through open discussions in real situations. Hence, it is essential to investigate the reliability of information published through various marketing tools by PHEIs. Even though several PHEIs maintain their social networking sites attractively to publish their academic, social and student activities, those were not able to reach and attract students effectively as expected. Prospective students often seek information such as employment prospects, psychosocial life, course difficulty and entrance requirements in addition to the characteristics of BD and PHEIs. The location factor, which has frequently mentioned in prior research about choice factors, was less influential in the Sri Lankan context. Thereby PHEVs need to identify factors which influence students' before the BD selection and to share information related to those factors through social media to attract students. As observing the online discussions may not be sufficient, the university marketers would also post the responses to Q \& A sessions to provide accurate information for the students' inquiries. Therefore, the role of PHEIs should lead to inculcates positive reinforcement among prospective students to connect with their updated official websites, social networking sites and student blogs to get information. Thereby, PHEIs could arrange some awareness programmes to promote the importance of seeking information through social media when they meet students and parents at open days and educational exhibitions. As the penetration of social media still plays a secondary role in providing information for prospective students in their BD choice compared to offline communication tools, educating stakeholders for the digital world is the utmost need in today's digital age using various technological advancement to reach potential students to facilitate with more informed information. Furthermore, it is essential to initiate a regulatory body to maintain the quality of 
PHEIs affiliated to foreign universities and especially to monitor the dropout rate of students from their respective BD programmes under various IDPs.

\section{References}

Abeygunawardena, K. A. V. (2018a). Influential Factors in Selecting a Bachelor's Degree from Private Higher Educational Institutes in Sri Lanka: A Study Based on Undergraduates of International Degree Programmes. PEOPLE: International Journal of Social Sciences, 4(2), 75-96. Retrieved from https://doi.org/10.20319/pijss.2018.42.7596

Abeygunawardena, K. A. V. (2018b). Towards an integrated framework for Bachelor's degree choice in Sri Lanka, Proceeding of the International Conference on Future of Education, 1(2),1-10. Retrieved from https://doi.org/10.17501/26307413.2018.1201

Abeygunawardena, K. V. (2018c). Influential Factors in Selecting a Bachelor's Degree from International Degree Programmes offered in Sri Lanka: perspective of Lecturers and Graduates. Proceedings of the International Conference on Education, 4(1), 51-61. https://doi.org/10.17501/icedu.2018.4106

Abeygunawardena, K. A. V. (2019). Students' Behavioural Patterns on Bachelor's Degree Choices in Sri Lanka: Heuristics?. PEOPLE: International Journal of Social Sciences, 4(3), 763-785. Retrieved from https://doi.org/10.20319/pijss.2019.43.763785

Alonderiene, R., and Klimavičiene, A. (2013). Insights into Lithuanian students' choice of university and study program in management and economics. Management: Journal of contemporary Management issues. 18(1), 122.

Bonnema, J., and Van der Waldt, D. L. R. (2008). Information and source preferences of a student market in higher education. International journal of Educational Management, 22(4), 314-327.

Briggs, S., and Wilson, A. (2007). Which university? A study of the influence of cost and information factors on Scottish undergraduate choice. Journal of Higher Education Policy and Management, 29, 57-72. Retrieved from https://doi.org/10.1080/13600800601175789.

Brown, C., Varley, P., and Pal, J. (2009). University course selection and services marketing. Marketing intelligence \& Planning, 27(3), 310-325. doi: 10.1108/02634500910955227.

Chapman, D. W. (1981). A model of student college choice. The Journal of Higher Education, 52 (5), 490-505. doi: $10.2307 / 1981837$.

Cubillo, J., Sánchez, J., \& Cerviño, J. (2006). International students' decision-making process. International Journal of Educational Management. 20(2), 101-15.

Dao, M.T.N., \& Thorpe, A. (2015). What factors influence Vietnamese students' choice of university? International Journal of Educational Management, 29(5), 666-681.

Fagerstrom, A., \& Ghinea, G. (2013). Co-Creation of Value in Higher Education: Using Social Network Marketing in the Recruitment of Students. Journal of Higher Education Policy and Management, 35(1), 4553. Retrieved from https://www.learntechlib.org/p/132030/.

Field, A. (2005). Discovering statistics using SPSS (2nd Ed.). London: Sage.

Galan, M., Lawley, M., \& Clements, M. (2015). Social media's use in postgraduate students' decision-making journey: An exploratory study. Journal of Marketing for Higher Education, 25(2), 287-312. doi:10.1080/08841241.2015.1083512.

Hanson, K., \& Litten, L. (1989). Mapping the road to academia: A review of research on women, men and college selection process. In P. Perun (Ed.), The undergraduate woman: Issues in education,73-98. Lexington: Lexington Books.

Hayes, T. J., Ruschman, D., \& Walker, M.M. (2009). Social networking as an admission tool: A case study in success. Journal of Marketing for Higher Education, 19(2), 109-124. doi:10.1080/08841240903423042.

Hemsley-Brown, J., \& Oplatka, I. (2015). University choice: What do we know, what don't we know and what do we still need to find out? International Journal of Educational Management, 29(3), 254-274. 
Hobsons. (2017). "Global international student survey", The changing dynamics of international student recruitment. retrieved from https://www.internationalstudentsurvey.com/.

Kimmel, A. J., \& Kitchen, P. J. (2013). WOM and social media: Presaging future directions for research and practice. Journal of Marketing Communications, 20(1-2), 5-20. doi:10.1080/13527266.2013.797730.

Knight, J. (2007). Internationalization: Concepts, Complexities and Challenges. In: Forest J.J.F., Altbach P.G. (eds) International Handbook of Higher Education. Springer International Handbooks of Education, vol 18. Springer:Dordrecht.

Knight, J. (2012). Student mobility and internationalisation: Trends and tribulations. Research in Comparative and International Education, 7, 20-33.

Kusumawati, A., Yanamandram, V. K., \& Perera, N. (2010). Exploring student choice criteria for selecting an indonesian public university: A preliminary finding. ANZMAC 2010 Doctoral Colloquium (pp. 1-27). Christchurch, New Zealand: ANZMAC. Accessed on August, 10th, 2018.

Mangold, W. G., \& Faulds, D. J. (2009). Social media: The new hybrid element of the promotion mix. Business Horizons, 52(4), 357-365. doi:10.1016/j.bushor.2009.03.002.

Maniu, I., \& Maniu, G. C. (2014). A model of students' university decision making behaviour. SEA - Practical Application of Science, 2(3), 431-436.

Maringe, F. (2006). University and course choice: Implications for positioning, recruitment and marketing. International Journal of Educational Management, 20(6), 466-479.

Mazzarol, T., \& Soutar, G. N. (2002). "Push-pull" factors influencing international student destination choice. International Journal of Educational Management, 16(2), 82-90.

Migin, M., Falahat, M., \& Khatibi, A. (2015). Conceptualizing the decision making process of international students in higher education. International Journal of Business and Social Science, 6(1), 119-126.

Misley, H., \& Vamos, A. (2017). Marketing in higher education: website analysis population system a based on Hungarian and international professionals. Hungarian Pedagogy,117(4), 365-380. doi: 10.17670/MPed.2017.3.365.

Moogan, Y. J., \& Baron, S. (2003). An analysis of student characteristics within the student decision making process. Journal of Further and Higher Education, 27(3), 271-287. doi:10.1080/0309877032000098699.

Obermeit, K. (2012). Students' choice of universities in Germany: Structure, factors and information sources used. Journal of Marketing for Higher Education, 22(2), 206-230. doi:10.1080/08841241.2012.737870.

Ozga, J., \& Sukhnandan, L. (1998). Undergraduate non-completion: developing an explanatory model. Higher Education Quarterly, 52(3), 316-333. Retrieved from https://doi.org/10.1111/1468-2273.00100.

Patti, C, H., \& Chen, C. H. (2009). Types of word-of-mouth messages: information search and credence-based services. Journal of Promotion Management, 15(3), 357-381. doi:10.1080/10496490903185760.

Rowe, J. (2014). Student use of social media: When should the university intervene? Journal of Higher Education Policy and Management, 36(3), 241-256. doi:10.1080/01587919.2014.899054.

Rutter, R., Roper, S., \& Lettice, F. (2016). Social media interaction, the university brand and recruitment performance. Journal of Business Research, 69(8), 3096-3104. doi:10.1016/j.jbusres.2016.01.025.

Saunders, M., Lewis, P., \& Thornhill, A. (2012). Research methods for Business students (6th ed.). Harlow: Pearson Education.

Simões, C., \& Soares, A. M. (2010). Applying to higher education: Information sources and choice factors. Studies in Higher Education, 35(4), 371-389. doi:10.1080/03075070903096490.

Soutar, G. N., \& Turner, J. P. (2002). Students' preferences for university: A conjoint analysis. International Journal of Educational Management, 16(1), 40-45.

Stephenson, A, L., Heckert, A., \& Yerger, D. B. (2016). College choice and the university brand: Exploring the consumer decision framework. Higher Education, 71(4), 489-503. doi:10.1007/s10734-015-9919-1. 
Tabachnick, B. G., \& Fidell, L. S. (2013). Using Multivariate Statistics (6th ed.). United Kingdom: Pearson. The UGC. 2016. University grants commission. http://www.ugc.ac.lk/html/downloads/stat_2016/Chapter\%202.pdf. Accessed: 2018-07-26.

Tavares, O., \& Cardoso, S. (2013). Enrolment choices in Portuguese higher education: Do students behave as rational consumers? Higher Education, 66(3), 297-309. doi:10.1007/s10734-012-9605-5.

Veloutsou, C., Lewis, J. W., \& Paton, R. A. (2004). University selection: Information requirements and importance. International Journal of Educational Management, 18(3), 160-171.

Venkatesh, V., Morris, M. G., \& Ackerman, P. L. (2000). A longitudinal field investigation of gender differences in individual technology adoption decision-making processes. Organizational Behavior and Human Decision Processes, 83(1), 33-60. Retrieved from https://doi.org/10.1006/obhd.2000.2896.

Voyer, P. A., \& Ranaweera, C. (2015). The impact of word of mouth on service purchase decisions: Examining risk and the interaction of tie strength and involvement. Journal of Service Theory and Practice, 25(5), 636-656. doi:10.1108/JSTP-04-2014-0070.

Vrontis, D., Thrassou, A., \& Melanthiou, Y. (2007). A contemporary higher education student-choice model for developed countries. Journal of Business Research, 60(9), 979-989. doi:10.1016/j.jbusres.2007.01.023.

Walsh, C., Moorhouse, J., Dunnett, A., \& Barry, C. (2015). University choice: Which attributes matter when you are paying the full price? International Journal of Consumer Studies, 39(6), 670-681.

Wilkins, S., \& Huisman, J. (2015). Factors affecting university image formation among prospective higher education students: The case of international branch campuses. Studies in Higher Education, 40(7), 1256-1272. doi:10.1080/03075079.2014.881347.

Wong, P., Lee, D., \& Ng, P. M. L. (2018). Online search for information about universities: A Hong Kong study. International Journal of Educational Management, 32(3), 511-524.

Yorke, M. (1999). Leaving early: Undergraduate non-completion in higher education. London: Falmer Press. Retrieved from https://doi.org/10.4324/9780203209479. 